\title{
An Adaptive Query based Product Recommendation System
}

\author{
Narendra M. \\ M.Tech Student \\ Dept of CS\&E \\ JSS S \& T U, MYSURU
}

\author{
P. M. Shivamurthy \\ Assistant Professor \\ Dept of CS\&E \\ JSS S \& T U, MYSURU
}

\begin{abstract}
Web has a tremendous growth in terms of both content and number of users, this has led to a serious problem of information overloading in which it is difficult for users to locate authentic information in the given time. Recommender Engines have been developed to address this problem, by guiding the users through the information and helping them find the right information. Traditional Recommender Engine sought to predict the 'rating' or 'preference' that a user would give to an item or social element they had not yet considered, this model is developed from the characteristics of an item or the user's social environment. Spatially Aware Recommender Engine on the other hand produces a location-aware recommender system that uses location based ratings to produce recommendations. This project will present the design, implementation, testing and evaluation of a recommender system with the solution for Limited resource situation and cold start problem using Hybrid filtering algorithm, Lesk based algorithm and Random algorithm.
\end{abstract}

\section{Keywords}

Recommendation system, limited resource situation, cold start problem

\section{INTRODUCTION}

With the popularization of the Internet and the development of E-Commerce, the structure of Ecommerce system became more and more complex. This situation made it hard for customers to find the products and services they want effectively. E-commerce recommendation is to take advantage of Ecommerce site to provide information and suggestions, to help consumers make purchasing decisions. Although the ECommerce recommendation system has been successful, it faces challenges with the development of Ecommerce. Nowadays, most popular E-Commerce Website, such as Amazon, adopt hybrid algorithm based on item-based recommended algorithm. Those recommender system are able to give out some recommendations for customer, but, from the view of consumers, there are still some problems which are suspected to be solved. Compare to existing E-Commerce recommendation system, following factors should be taken into account:

1) Limited resource. For instance, personal recommendation for limited product with special lowest price in special offer period. Those kinds of products should be recommended with priority, so that customers can buy with pleasure.

2) Cold start. It's a problem for customer who first time visit the E-Commerce website which are not well solved in existing E-Commerce recommendation system.

An effective E-Commerce recommendation system can give out effective recommendations for customers which can be approved by customers as far as possible. Customers can get benefits, at the same time, the trading volume can be enhanced. Limitations of Existing System

i. Unable to solve cold start problem.

ii. Limited resource situation is not properly handled.

\section{PROBLEM STATEMENT}

This paper shall focus on development and evaluation of a recommender system. The proposed system discusses the Limited resource situation and cold start problem which are the necessary solutions that are not present in the current $\mathrm{E}$ commerce application.

The Scope and objectives are listed below:

i. Proposed system is a E-Commerce application

ii. The Web application aims at implementing the recommendation system for consumers to find the product they want.

iii. The Web application mainly consists of 3 models namely - User Model, Recommended Model and Recommendation Algorithm.

The Web application give solutions for problems of existing E commerce recommendation system such as; Limited resource situation and cold start problem.

\section{PROPOSED SYSTEM}

The proposed system proposes the following modules.

i. Recommendation of products based on AOI.

ii. Query based search.

iii. Customers with neighbors

iv. Customers with no neighbors and no history.

Query Based Search

This module discusses about query search where a lesk based algorithm is used.

Classification Rules

Step: 1 Scan Dataset. (Data preprocessing and data extraction)

Removing the junk data/noisy data and extraction of data needed for mining or processing.

i. Removing irrelevant data

ii. Extraction of relevant data

iii. Extraction of necessary data for processing

Step: 2 Retrieve keyword dataset (which are predefined).

Step: 3 Retrieve user query from E Commerce Website. 
Step: 4 Use classifier to extract metadata from the content of query.

i. For each entry Ui [queries] in buffer [storage server] do

ii. Trace all keywords, using the following steps

a. Tokenization [Keyword extraction method removing the stop words and retrieving the keywords]

b. Remove punctuation, special characters, number etc.

iii. Clustering the keywords (grouping the similar objects)

a. By comparing with the predefined dataset (product categories and sub categories)

b. String comparison and identify the product category and sub category.

Step: 5 Depending on the result of the previous step, products will be extracted and displayed for the user.

\section{Customers with Neighbors}

\section{Recommendation Process}

On the basis of collaborative filtering principle, the recommendation process of customer's attractions can be divided into three steps;

1) The representation of user (customer) information. The purchasing history of attractions by customer need to be analyzed and modeled.

2) The generation of neighbor users (customers). The similarity of customers can be computed according to the buying history data and the collaborative filtering algorithm. A neighbor customer list can be calculated on the basis of known similarities.

3) The generation of attraction recommendations. Top-N attractions will recommended to the customer according to the buying history of his neighbors.

\section{Generation of Neighbors}

1. Neighbor users generated mainly based on the similarity between each user.

2. Suppose that the set of all customers $C=\{C 1, C 2 \ldots C n\}$, for each customer $\mathrm{Ci}(\mathrm{i}=1,2 \ldots \mathrm{n})$, the system can calculate the neighbors list including the top $\mathrm{N}$ customers which similarity is higher than the given threshold.

3. There are mainly three ways to measure the similarity between customers, including Cosine method, Correlation similarity method and Adjusted Cosine method.
Table 6.1- Purchasing History of the Customer

\begin{tabular}{|c|c|c|c|c|c|}
\hline \multirow{2}{*}{ Customers } & \multicolumn{5}{|c|}{ Attractions } \\
\cline { 2 - 6 } & I1 & I2 & I3 & I4 & I5 \\
\hline C1 & 1 & 0 & 1 & 1 & 1 \\
\hline C2 & 0 & 1 & 1 & 1 & 1 \\
\hline C3 & 1 & 0 & 1 & 1 & 0 \\
\hline C4 & 0 & 1 & 1 & 0 & 1 \\
\hline C5 & 0 & 1 & 0 & 1 & 0 \\
\hline
\end{tabular}

The below Mathematical equations are used to calculate the neighbors of the customers.

$\operatorname{Sim}(\mathrm{Ci}, \mathrm{Cj})=|\mathrm{Si}|$ Union $|\mathrm{Sj}| /|\mathrm{Si}|$ Intersection $|\mathrm{Sj}|$

Based on (1) and Table 6.1, the similarity between $\mathrm{C} 1$ and $\mathrm{C} 2$, $\mathrm{C} 1$ and $\mathrm{C} 3, \mathrm{C} 1$ and $\mathrm{C} 4, \mathrm{C} 1$ and $\mathrm{C} 5$ are calculated and as follows:

$\operatorname{Sim}(\mathrm{C} 1, \mathrm{C} 2)=|\mathrm{S} 1|$ Union $|\mathrm{S} 2| /|\mathrm{S} 1|$ Intersection $|\mathrm{S} 2|=3 / 5=0.6$ (2)

Table 6.2-Purchasing history of neighbor customers

\begin{tabular}{|c|c|c|c|c|c|}
\hline \multirow{2}{*}{ Customers } & \multicolumn{5}{|c|}{ Items } \\
\cline { 2 - 6 } & I1 & I2 & I3 & I4 & I5 \\
\hline C1 & 1 & 0 & 1 & 1 & 1 \\
\hline C2 & 0 & 1 & 1 & 1 & 1 \\
\hline C3 & 1 & 0 & 1 & 1 & 0 \\
\hline Total & 2 & 1 & 3 & 3 & 2 \\
\hline
\end{tabular}

$\operatorname{Sim}(\mathrm{C} 1, \mathrm{C} 3)=|\mathrm{S} 1|$ Union $|\mathrm{S} 3| /|\mathrm{S} 1|$ Intersection $|\mathrm{S} 3|=3 / 5=0.6$

$\operatorname{Sim}(\mathrm{C} 1, \mathrm{C} 4)=|\mathrm{S} 1|$ Union $|\mathrm{S} 4| /|\mathrm{S} 1|$ Intersection $|\mathrm{S} 4|=2 / 5=0.4$

$\operatorname{Sim}(\mathrm{C} 1, \mathrm{C} 5)=|\mathrm{S} 1|$ Union $|\mathrm{S} 5| /|\mathrm{S} 1|$ Intersection $|\mathrm{S} 5|=1 / 5=0.2$

If the value of threshold Theta is set to 0.5 , then the neighbors of $\mathrm{C} 1$ are $\mathrm{C} 2$ and $\mathrm{C} 3$.

\section{Generation of Recommendations}

Recommendations of attractions are computed by the purchasing times of neighbors. According to the calculation above, the neighbors of customer $\mathrm{C} 1$ are $\mathrm{C} 2$ and $\mathrm{C} 3$, all the purchasing history of all the attractions so as to summary the most popular ones. As listed in Table 2, maximal purchasing times of neighbors are item I3 and I4 are calculated.

When new customers enter the system, there is usually insufficient information to produce recommendation for them, because there is no purchasing history of the new customers. The usual solution of the cold start problem is similarity calculation between each user by profile information, such as age, sex, professional, income, etc. 
Customers with no neighbors and no history (Cold Start Problem)

i. Area of interest of a customer is considered.

ii. Similar users of same interest and their transactions are considered.

iii. Calculate the trading volume of each product

a. Trading volume is calculated using the following formulae;

b. $\quad$ Volume $=$ transaction containing that product/total number of transactions

iv. Store it in array list, then sort and reverse.

v. Retrieve top 10 products as recommendation result.

\section{WORKING AND RESULTS}

The below are the Input and Output snapshots

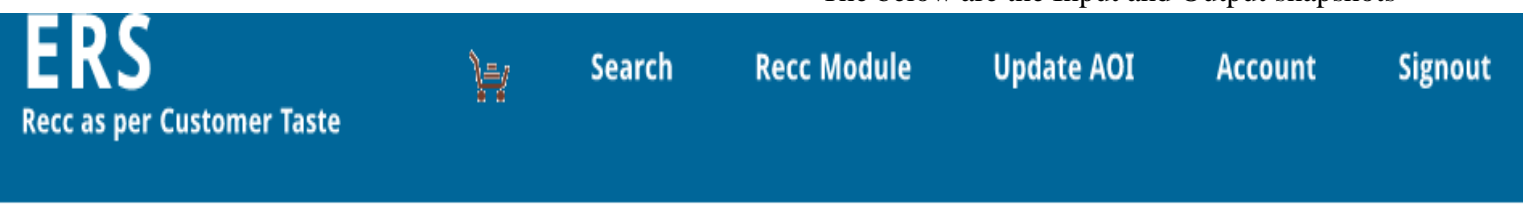

\section{Member}

Browse Products

\begin{tabular}{l}
\hline Purchased History \\
\hline Feedbacks
\end{tabular}

Product Ratings

\section{Browse Products (Quantity>5)}

\section{Item Category Men's Clothing V Item SubCategory}

T shirts Men Fashion curling short sleeved Slim

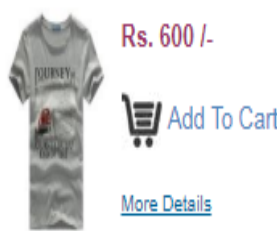

More Details
Kcoyster men striped gingham shirts

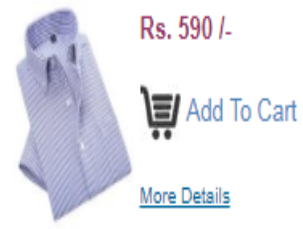

- All - $\quad$ -

JBN Creation Grey Matka Silk Mod Nehru Jacket

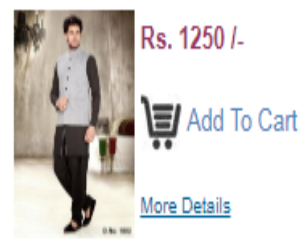

\section{New Looks Mens blue Linen Kurta}

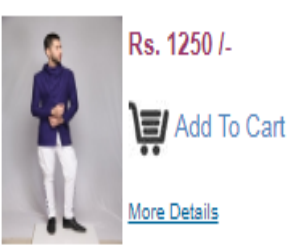

New Looks Mens maroon Linen Kurta Men's Long Sleeve Solid Linen Shit Pyjama

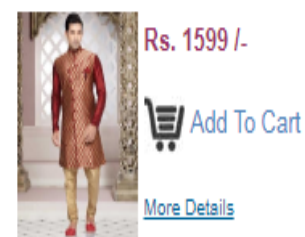

Rs. 1060 \%

䞍 Add To Cart

Fig 1: View of Items of E-commerce application 
Member

\begin{tabular}{l}
\hline Browse Products \\
\hline Purchased History \\
\hline Feedbacks \\
\hline Product Ratings
\end{tabular}

Product Ratins

Query based Products Search

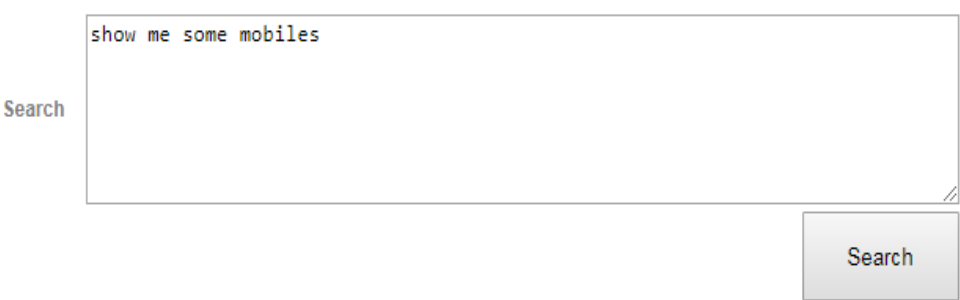

Moto G4 plus [Rating: 7]

Moto G5 plus [Rating: 4]

Moto G4 play [Rating: 3]

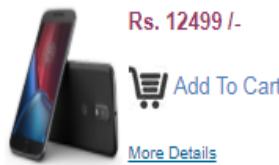

Rs. 14999 /.

湆 Add To Cart

More Details

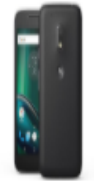

Rs. 7999 /.

贾 Add To Cart

More Details
Samsung Galaxy A5 (Champagne Gold, 16 GB) [Rating: 0]

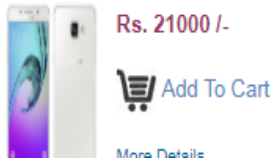

Samsung Galaxy J7 Prime SM-G610F (Gold, 16GB) [Rating: 0]

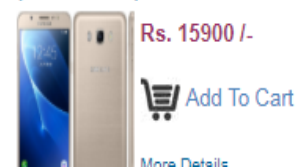

Samsung Galaxy Note 4 (Black) [Rat 0

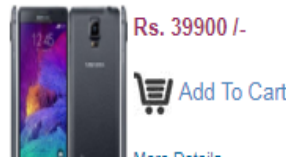

Fig 2: Results of Query based product search

\section{Member}

Browse Products

Purchased History

Feedbacks

Product Ratings

\section{RECOMMENDATION FOR U (QUANTITY<=5)}

Case 1: Recommendation of Products with History with Neighbours

\begin{tabular}{|c|c|c|c|c|c|c|c|}
\hline SLNo & Photo & $\begin{array}{l}\text { Limited } \\
\text { Quantity }\end{array}$ & $\begin{array}{l}\text { Product } \\
\text { Name }\end{array}$ & $\begin{array}{l}\text { Item } \\
\text { Cost }\end{array}$ & Description & $\begin{array}{l}\text { Purchased } \\
\text { Count }\end{array}$ & Cart \\
\hline 1. & & 2 & $\begin{array}{l}\text { Long } \\
\text { Sleeve tee } \\
\text { New } \\
\text { Arrivel } \\
\text { Fashion } \\
\text { Cotton } \\
\text { Anti-Wr }\end{array}$ & 580 & $\begin{array}{l}\text { Sleeve Length:Full Style:Casual Pattern } \\
\text { Type:Striped Feature:Anti-Wrinkle Type:Regular } \\
\text { Material:Cotton }\end{array}$ & 2 & AddToCart \\
\hline 2. & & & $\begin{array}{l}\text { Enticer } \\
\text { Black Dial } \\
\text { Mens } \\
\text { Watch }\end{array}$ & 1299 & $\begin{array}{l}\text {-Dial Color. Black -Case Shape: Round -Dial } \\
\text { Glass Material: Mineral -Band Color. Silver -Band } \\
\text { Material: Stainless Steel -Watch Movement Type: } \\
\text { Quartz -Watch Display Type: Analog -Water } \\
\text { Resistance Depth: } 50 \text { meters }\end{array}$ & 2 & AddToCart \\
\hline 3. & & 3 & \begin{tabular}{|l} 
Spring \\
Summer \\
2017 new \\
Patchwork \\
white \\
button \\
down
\end{tabular} & 720 & $\begin{array}{l}\text { Item Type: Shirts Gender:Men Fabric Type:Twill } \\
\text { Sleeve Length: Full Shirts Type:Dress Shirts } \\
\text { Style: Buiness Formal Collar: Turn-down } \\
\text { CollarMaterial:Cotton,Polyester Closure } \\
\text { Type:Single BreastedModel Number.114 Sleeve } \\
\text { Style:RegularPattern Type:twill Material:40\% } \\
\text { cotton+60\% polyester }\end{array}$ & 1 & AddToCart \\
\hline 4. & & 5 & $\begin{array}{l}\text { Classical } \\
\text { Design } \\
\text { Cotton } \\
\text { Men Dress } \\
\text { Shirts }\end{array}$ & 850 & $\begin{array}{l}\text { Item Type:Shirts Gender:MenPattern } \\
\text { Type:SolidSleeve Length:FullShirts Type:Dress } \\
\text { ShirtsStyle:dress men shirtsCollar:Turn-down } \\
\text { CollarFabric } \\
\text { Type:BroadclothMaterial:Cotton,PolyesterClosure } \\
\text { Type:Single BreastedModel Number:DMBrand } \\
\text { Name:PINMASleeve }\end{array}$ & 1 & AddToCart \\
\hline
\end{tabular}

Fig 3: Limited resource situation considering with history and with neighbors 


\section{Member}

\begin{tabular}{l}
\hline Browse Products \\
\hline Purchased History \\
\hline Feedbacks \\
\hline Product Ratings \\
\hline
\end{tabular}

\section{RECOMMENDATION FOR U (QUANTITY<=5)}

\section{Case 3: No History for the User, So We Consider Customer AOI}

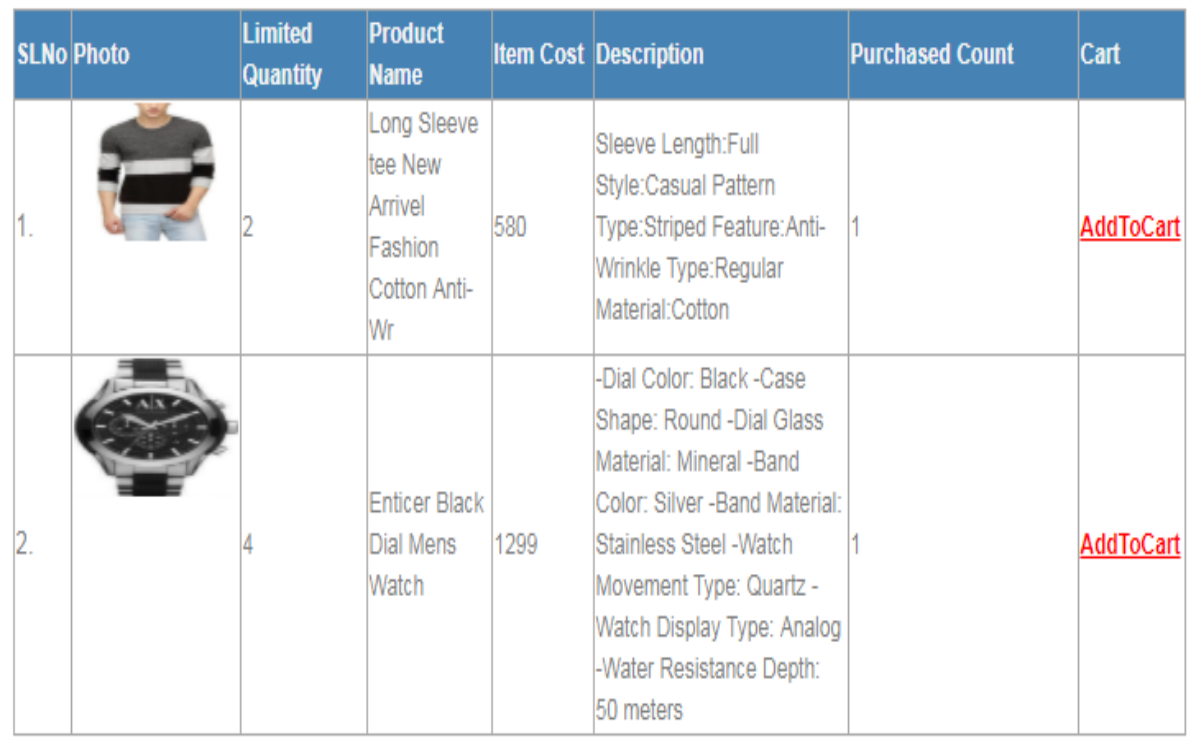

Displaying Neighbour Customers

Fig 4: No history for the customer so considered AOI (Cold Start Problem)

\section{CONCLUSION}

Nowadays, recommendation systems are increasingly gaining notoriety due to their high number of applications. The users cannot manage all the information available on Internet because of this is necessary some kind of filters or recommendations. Also the companies want to offer to the user specific information to increase the purchases. Recommender systems offers new opportunities of retrieving personalized information on the Internet. It also helps to alleviate the problem of information overload which is a very common phenomenon with information retrieval systems and enables users to have access to products and services which are not readily available to users on the system. In summary, the objective of a recommender system typically is to recommend items that best for customer's personal preferences. Collaborative filtering systems generates recommendation based on user-user similarity. A new user encounters a serious problem in collaborative filtering approach. Since the system does not have any data about the new user preferences, it could not provide any personalized recommendation for him/her. With the development of ECommerce, personalized recommendation has been paid more and more attention. Limited resource situation and cold start problems have not been well considered in existing $\mathrm{E}$ Commerce recommendation system. This paper proposes limited resource table method, an algorithm based on limited resource and a solution to cold start problem, which can enhance the effect of recommendation system. The solutions proposed in this paper are meaningful for E-Commerce websites and recommendation system. In the future, more and more factors will be taken into account in E-Commerce recommendation system.

\section{REFERENCES}

[1] "A collaborative filtering recommendation algorithm based on user interest change and trust evaluation", Zhimin Chen, yijiang, yaozhao international journal of digital content technology and its applications volume 4 , number 9, december 2010.

[2] "Cold-start Problem in Collaborative Recommender Systems: Efficient Methods Based on Ask-to-rate Technique", Mohammad-HosseinNadimi-Shahraki and MozhdeBahadorpour Journal of Computing and Information Technology - CIT 22, 2014, 2, 105-113 doi:10.2498/cit.1002223.

[3] "A Survey on Personalized Service Recommendation Systems", Devdatta Godbole1 Manish Narnaware International Journal of Engineering Research \& Technology (IJERT), Vol. 5 Issue 02, February-2016

[4] "Toward the Next Generation of Recommender Systems: A Survey of the State-of-the-Art and Possible Extensions", GediminasAdomavicius, Alexander Tuzhilin ieee transactions on knowledge and data engineering, vol. 17, no. 6 , june 2005 